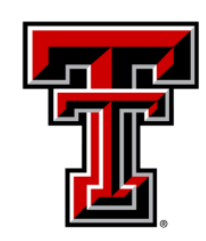

TEXAS TECH UNIVERSITY

Libraries"

\title{
CoOperation and Competition at the Reference DeSK
}

\section{The Texas Tech community has made this publication openly available. Please share how this access benefits you. Your story matters to us.}

\begin{tabular}{|l|l|}
\hline Citation & $\begin{array}{l}\text { Quinn, B. (2001, January). Cooperation and Competition at the } \\
\text { Reference Desk. Reference Librarian, 34(72), 65. } \\
\text { https://doi.org/10.1300/J120v34n72_07 }\end{array}$ \\
\hline Citable Link & $\underline{\text { http://hdl.handle.net/2346/487 }}$ \\
\hline Terms of Use & $\underline{\text { CC-BY }}$ \\
\hline
\end{tabular}


Many libraries, both academic and public, utilize a practice known as "double coverage" at the reference desk. This means assigning two librarians to work at the desk together rather than one. The most common rationale for having two librarians working at the same time is improved ability to handle patron traffic during high volume periods. The presence of a second librarian can also be helpful when telephone reference questions need to be answered. In addition to these quantitative considerations, there is an implicit assumption that the two librarians may collaborate at times and assist one another in answering questions, thereby enhancing the quality of reference service. This latter assumption is especially interesting because it brings to light a seldom recognized yet extremely important aspect of reference work. The two librarians who have been assigned to work together have been placed in a unique relationship to one another. Like other dyadic relationships such as friends, teammates, and spouses, there is suddenly the potential for a whole range of behaviors, attitudes, and emotions that librarians manifest toward each other. These can range from simple awareness of the other to more complex interactions that can be potentially negative--such as criticism, competition, or oneupmanship—or positive, such as praise, support and collaboration.

It is the purpose of this study to examine the emotional and behavioral dynamics of cooperation and competition between reference desk partners from a practical standpoint. The emphasis will be on not just describing the nature of cooperative and competitive behavior, but on changing unproductive relationships, and actively developing positive, supportive relationships that make sharing desk work a valued experience that can enrich the development of not only librarians but the users themselves. 
Why are cooperative and competitive behaviors so important to reference work? The reason is that a strongly cooperative or competitive relationship between two librarians can have a profound effect both on the quality of librarians' working lives and on the quality of reference service that the user receives. Cooperation and competition play a critical role in reference outcomes because negative competitive interactions between librarians can undercut not only their individual abilities but also the possibility of cognitive and intellectual synergy emerging if their relationship were more cooperative. It is the user who ultimately stands to lose the most when librarians are unable to relate well to one another at the desk.

Given the importance of cooperation and competition in reference work, it seems odd that no one appears to have written about it in the library literature. This may be because in the course of reference work, cooperation and competition may manifest themselves in very subtle, imperceptible ways, rather than overtly. It may also be the case that librarians presume themselves to be good by nature, and thus avoid any aspects of the profession that may draw attention to the fact that librarians are as human as anyone else, with all the imperfections and weaknesses that come with being human. In general, there appears to be a cognitive bias in the reference literature, with most articles focusing on reference work as a largely intellectual process in which emotions have little place.

The library literature on cooperation and competition stands in sharp contrast to the literature in the social sciences. There are hundreds of psychological and sociological studies that have to do with some aspect of cooperation and competition. Most of these, however, are of little practical value. Many of the psychological studies are rigidly 
controlled lab-based experiments that are not easily generalized to everyday work situations (Good, 1991). The business literature is somewhat better in this regard, but much of it suffers from the problem that it is based on anecdotal case studies or impressionistic accounts that are difficult to generalize to a wide variety of situations. There are, however, a handful of studies from each of these fields that may shed some light on how librarians become cooperative or competitive in their relations and how they can change those relationships when they become unsatisfactory.

\section{SOCIAL AND PSYCHOLOGICAL FACTORS}

When two librarians share the desk, they each bring with them a lifetime of social and psychological "baggage" or influences that come to bear on the relationship that develops between them. While it is beyond the scope of this article to attempt to enumerate all of these, it is nonetheless important at least to note some of the more important factors affecting librarians' predispositions toward cooperativeness and competitiveness in shared reference work. To do otherwise would be to suggest that reference work occurs in a vacuum, or that librarians live apart from the larger world.

Librarians, like most other people, live in an intensely competitive society (Argyle, 1991). They have been socialized from an early age to compete with one another. Very young children compete with each other in play, and even siblings engage in rivalry to compete for their parents' approval (Mander, 1991). Our educational system is designed to foster individuality and competition among students. Many of the most popular extracurricular activities, such as sports, reinforce and reward competitive behavior in children and adolescents. By the time a person emerges from the educational 
system and is ready to enter the world of work, they have internalized many values of the larger competitive society of which they are a part.

There are, of course, variations on the extent to which particular social groups will be more inclined to behave cooperatively or competitively. Gender, class, and ethnicity can all play a role in how individuals will behave. Women, for example, have traditionally been socialized to be more cooperative, supportive, and empathetic than men (Knight, 1989). Yet this traditional socialization process may be changing as women are increasingly being encouraged to pursue the same goals as men in virtually all fields of endeavor, and to compete with them for the same rewards. The women's equality movement has helped enable women to compete both with other men and each other, which may have an overall effect of making our culture even more competitive.

In addition to these social factors, there are many psychological factors that can influence the degree to which an individual is competitive or cooperative. One of the more important ones is locus of control-the degree to which a person believes that she can control her fate and advance her career through her own behavior. The stronger the belief in an internal locus of control, the more competitive a person is likely to act (Lester, 1992). Another important factor is a person's need to achieve. The greater a person's need to achieve, the more likely he is to act competitively (Ward, 1995). A third important factor is a person's orientation toward others. Selfish, uncooperative personalities tend to regard others as objects to be manipulated for one's own self benefit, while personalities with a more caring, altruistic orientation tend to regard others as persons rather than objects, and try to help them with the idea of genuinely enhancing their welfare rather than for selfish reasons (Cialdini, 1987). 
Various instruments have been developed to measure the competitive personality. Individuals that score high on these tests are considered by psychologists to be competitive. One such test is called the Competitiveness Index. It consists of a series of statements that subjects label "true" or "false." To identify the competitive personality, the Competitiveness Index includes statements such as "I get satisfaction from competing with others." "Games that have no clear cut winners are boring." "I enjoy competing against an opponent," and "When I play a game I like to keep score" (Houston, 1992). In other words, a certain type of personality is predisposed to be competitive.

\section{COMPETITIVE DESK BEHAVIORS}

Given these social and psychological factors that predispose individuals to behave competitively, it is not surprising that competition between librarians can emerge at the reference desk. The very nature of the situation lends itself to competition, because it typically involves two librarians who, for all intents and purposes, provide the same kind of service in a fairly similar manner. From the purely instrumental standpoint of the patron, they might as well be the same, and it appears that approaching one librarian for help should make no more difference than choosing one supermarket checker over another.

Yet patrons do sometimes have preferences for a particular kind of librarian, for female over male, young over old, black over white, neat over casual, and so forth. Librarians generally enjoy working with the public and can readily notice if patrons gravitate toward themselves or a partner. Popularity with patrons can easily become a source of rivalry, even though it may have little to do with expertise. It is human nature 
for librarians who think they are not getting as much "business" as their partner to wonder what exactly it may be that users see in their colleague that they themselves do not possess. These covert comparisons can breed envy and frustration, because popularity with patrons is not something that can be readily controlled by the librarian.

Sometimes a librarian will attempt to compete for patrons by engaging in various kinds of "barkering" behaviors at the desk. Typically, this involves one librarian trying to outdo the other by actively seeking out users in an effort to engage them or draw them in to a reference transaction. It can involve the use of body language, eye contact, verbal entreaties and similar kinds of "in your face" actions that are designed to give them an edge over a more passive colleague who simply waits for a patron to approach. This sort of overt solicitation can, if taken to an extreme, reduce reference service to a kind of popularity contest.

The potentially competitive nature of the reference desk situation is magnified by the public aspect of reference work. Serving at the desk can be thought of as a kind of public performance, in which the two librarians are "onstage" and in full view of not only each other but the users as well (Goffman, 1959). When approached by a user, the librarian is expected to "perform," i.e. to provide assistance to the patron that helps them find the information they need. Because the reference transaction can be seen as a performance that may be observed by the other librarian as well as users, there is a certain pressure to perform well, to give a complete and accurate answer in as direct a way as possible. Each librarian wants to "look good," to appear knowledgeable and competent in the eyes of her colleague and other patrons as well. Any sort of hesitancy or equivocation on the part of the librarian who responds to a user may be interpreted as a 
sign of ineptness or ignorance by colleagues or users. This can be embarrassing to a librarian, even though it may be nothing more than a momentary lapse of memory. The competitive aspect of reference work is fueled not only by the performance nature of the work itself, but also by the inevitable fact that not all reference librarians have equal knowledge of all areas. At some point in the course of working on the desk together, the librarians will encounter a question from a user about which one librarian knows more than the other. Such instances can occur any number of times during a shift on the desk, and these knowledge inequalities can themselves become a source of competition between two desk partners. It is easy to criticize the adequacy of a colleague's answer if one knows more about the subject, and if one believes that one's colleague has provided an insufficient answer, there may be a great temptation to interrupt another's transaction and attempt to interject additional information.

The motive for intervening in another librarian's transaction may be purely altruistic and intended solely for the purpose of helping the user, but that is not always the case. The public nature of the work makes it all too easy to look like an expert and "score points" with users by outdoing a colleague and providing a better or more complete answer. Unfortunately, this usually occurs at the expense of the colleague, who stands to "lose face" in the eyes of the colleague and users who may be present. Colleagues who feel hurt or slighted may be encouraged to regain status and redeem their reputation by engaging in similar one-upmanship behaviors at the next available opportunity. There is the potential for these kinds of competitive behaviors to escalate if allowed to go unchecked, because even cooperative individuals will adjust their level of cooperation to match that of their partners (Kelley and Stahelski, 1970). 
Often the librarian who feels slighted cannot tell what the motive of the intervening librarian is. The librarian only knows what it feels like to be bested by a colleague, and may consider it rude and unprofessional. This can lead to further deterioration of the relationship between the two desk partners. In extreme cases, there may be a complete breakdown of communication between the two librarians with no communication occurring at all unless absolutely necessary.

Even in situations in which two librarians have equal knowledge to answer a question there is the potential for competitive behavior to emerge. In these cases, librarians may compete to see who can produce the answer first, or who can get to it quickest. This sort of competition occurs most frequently with easily answered questions with fairly obvious answers. Rapid response then becomes the measure of a librarian's prowess rather than simply finding the answer or giving the most complete answer. Reference service can take on a quiz show air in which speed matters more than thoughtfulness.

Knowledge and responsiveness are just two areas in which reference desk partners may compete. Where a librarian sits may be a source of competition, with two librarians competing for the most prominent spot (Wollman, Kelley, and Bordens, 1994). Reference desk furniture can be a source of contention, such as who gets the most comfortable chair. Patrons can be a source of competition, particularly choice patrons like faculty or graduate students who are likely to ask interesting questions. The type of question asked can also be cause for competition, with the loser likely getting stuck with a "printer is out of paper" level question. Librarians may even compete over the medium 
by which the question is conveyed, with live questions often being preferred over telephone questions.

With so many ways to compete and things to compete over at the reference desk, it is perhaps surprising that librarians ever cooperate or collaborate. Yet such prosocial behavior can and does occur, and in rare instances two librarians can even achieve an almost ideal synchrony and synergy that would not be possible to obtain from either individual alone (Csikszentmihalyi, 1997). What kind of conditions foster such a duet? Are there ways to change a negative relationship at the desk? The following section will examine some ways of increasing cooperativeness between reference partners.

\section{INTERVENTIONS TO FOSTER COOPERATION}

Not surprisingly, much of the research conducted on cooperation and competition between partners comes from the literature on conflict, interpersonal relationships, and couples therapy. Psychologists and sociologists working in these areas have written many books and articles that offer helpful interventions for managing competition and conflict in dyadic relationships. Many of these interventions seem applicable to a wide variety of settings and situations, so it will be worthwhile to take a closer look at some of these and see how they might apply to working at the reference desk.

Most of these interventions fall into two broad categories: cognitive interventions and behavioral interventions. Cognitive interventions can be useful for changing one's thoughts and feelings about one's partner and one's situation. Behavioral interventions are helpful in changing the way one acts toward one's partner. Any attempt aimed at changing a competitive situation to a cooperative one should begin with cognitive 
interventions. By changing one's cognitions first, it then becomes easier to change one's behavior.

The librarian's initial encounter with a competitive partner at the reference desk may serve as an illustration. Such an encounter will have a tendency to create a strong psychological reaction in the non-competitive partner. Negative, vulnerable, defensive thoughts arise in the mind and can generate feelings ranging from anxiety and anger to shock and disappointment. These thoughts are immediate and reactive in nature, and cognitive interventions can be an effective way to short circuit them. The following cognitive interventions may prove particularly useful in contending with a competitive reference partner.

\section{COGNITIVE RESTRUCTURING}

In a competitive situation, both partners will tend to resist making any changes in their behavior. There is a tendency for partners to be upset, to blame the other person for the problem, and to adopt a rigid mindset that insists that the other person should change first. Given that each partner's beliefs about the situation may be somewhat irrational and unrealistic, it is first necessary to change those beliefs, or at least the beliefs of one of the two partners. One of the partners has to cognitively grasp that the situation cannot change unless there is a realization that both are actually contributing to maintaining the

problem by their inflexible interpretations of the situation (Baucom, 1986). This can only be accomplished by challenging and rethinking one's basic expectations and assumptions about the relationship. 


\section{SELF-EFFICACY}

In order for a competitive situation to be changed to a cooperative one, cognitively restructuring one's thoughts to believe that it is one's own responsibility to change the situation is not enough. It is also necessary to believe that one has the ability to effectively change it, which is know as self-efficacy (Magaletta, 1999). Librarians faced with a competitive partner must believe that engineering a cooperative outcome is under their control. Otherwise it becomes too easy to become resigned to the situation or succumb to ineffective and counterproductive behaviors such as arguing, avoidance, or

withdrawal. Passivity, futility and defeatism will not lead to any behavioral change and it may at times be necessary for a librarian to muster the will needed to act in the face of an aggressive and inconsiderate partner.

\section{THOUGHT STOPPING}

Anyone who encounters a competitive partner at the reference desk will likely experience a variety of negative thoughts. Thinking that one's partner is selfish or ruthless will only generate more animosity. Ruminating about one's misfortune in being stuck with such a partner is similarly unconstructive. Yet it is natural to think such thoughts, particularly if one feels under stress, and negative thinking tends to generate additional negative thought and can become automatic and obsessive if not checked immediately. Thought stopping is an intervention that allows the librarian to break a negative thought train by covert interruption of the rumination process (Burk, 1985). Whenever one finds oneself thinking harshly critical thoughts, one can mentally shout 
"stop" to oneself to refocus one's thinking on one's work. This simple common-sense

procedure can prevent one from being overcome by one's own internal "noise" resulting from the stress of being in a competitive situation.

\section{SELF-OBSERVATION}

Entering a competitive situation in which one is in conflict with one's desk partner, it is easy to succumb to one's immediate impulses and emotions. Rather than instantly reacting emotionally with anger, fear, or defensiveness, it is helpful to pause, take a deep breath, and mentally step back from the situation and try to observe one's reaction to it. Watching one's mind and noting one's feelings may seem difficult initially, but with a bit of practice, it can be learned (Guidiano, 1995). Mentally detaching and observing how one talks to the partner, how one feels toward them, and how one talks to oneself about the interaction can give one considerable perspective on the dynamics of the situation and how to control it. Self-monitoring prevents one from being engulfed or overwhelmed by the situation so that one has time to think and reflect.

\section{REFRAMING}

Having a desk partner second-guess one or try to outdo one at the desk is enough to make one view the situation in a very negative way. Yet it is possible to reframe the situation, to alter one's conceptual view or framework of it, in such a way that it appears more manageable and changeable. For example, instead of viewing one's partner as the adversary, one can view him as a potential ally with whom one may possibly achieve mutual success. The competitive desk situation itself may be reframed as a means of 
promoting contact and involvement, and thus viewed in a most positive light. Another way to reframe the situation would be to view it as a different kind of competition in which each librarian is competing with herself rather than with each other to help instill more of a sense of teamwork and cooperation. Once one has reframed the situation, it is much more difficult to psychologically revert to the old view of things as insidious and insurmountable (Bagwell-Reese, 1997).

\section{ROLE REVERSAL}

The librarian who must contend with a competitive desk partner is likely to seek the moral high ground and perceive the situation in idealistic terms. The problem with thinking in terms of "what should be" or "what is right" is that it defines the situation in one's own terms rather than those of one's partner. In fact, a better way to effectively influence the other person's behavior may be to empathize rather than moralize. One needs to fully understand the other person's world, and may realize, for example, that the person who seems so cutthroat may actually be acting out of fear of not getting a good performance evaluation. A good way to empathize is to use a technique called role reversal. It involves putting oneself in the role of the other person and experiencing his world and his point of view as fully as possible (Carlson-Sabelli, 1989). Role reversal helps to eliminate misperceptions and misunderstandings that interfere with the process of cooperation. It also helps to quell anger and aggressive reactions that may result from being subjected to competitive forms of aggression by one's partner. 


\section{ATTRIBUTIONAL STYLE}

An important factor in determining the degree of competitive conflict in a relationship is each partner's attributional style. Attributions are the ways in which partners explain each other's behavior. The more one partner attributes the other partner's behavior to internal negative qualities of that partner, the less cooperative and smooth the relationship tends to be. Negative attributions usually call into question a partner's character and portray her behaviors as deliberate, selfish, and aggressive. A partner may develop a negative set of feelings toward the other person that suggests that the other person is responsible for negative events that occur in the relationship. The attributions become a standardized way or "style" of explaining everything negative that occurs in the relationship. The more rigid and predictable the attributional pattern, the more likely it is that the partners will be less open to responding to each other in flexible ways. Instead of genuinely looking at the partner's actual behavior, they are focusing on their own cognitions about the person. One's behavior toward the person cannot change unless one's cognitions change first, and negative cognitions only increase the possibility of negative behavior.

\section{NONVERBAL COMMUNICATION}

The most basic way a partner can convey a cooperative approach to reference desk work is through physical gestures. Body language can be used to communicate that one is interested in working closely together with one's partner in a collaborative effort. Standing or sitting close to one's partner, turning toward them, leaning forward, increasing gaze, looking interested, using a friendly tone of voice, and smiling are all 
cues that signal one is interested in a joint effort (Newton, 1990). Beyond one's basic bodily orientation, one can also use nonverbal communication to compensate for a lack of cooperation on the part of one's partner. A cold, disinterested partner is likely to respond more favorably to friendly nonverbal initiatives than to a partner who behaves neutrally or in an aloof, aversive way.

\section{MODELING}

One of the best ways to elicit cooperative behavior in one's desk partner is to model that behavior oneself. Although it might seem like modeling cooperation might open one up to being taken advantage of by a competitive partner, the opposite response is more likely. In one psychology experiment that tested the effects of modeling on cooperation, researchers discovered that subjects would cooperate with a model they had seen behave cooperatively, even if it looked like the person could be exploited (Braver, 1976). Competitive individuals often view all persons as being much like themselves (i.e. competitive) and by demonstrating that there is a good possibility that cooperative initiatives will not be taken advantage of, one's partner may feel secure enough to attempt to make some initial gestures toward cooperation.

\section{SELF-DISCLOSURE}

With a competitive partner, it is natural to react by becoming defensive and closed and trying to remove oneself from the other person as much as the immediate situation will permit. Unfortunately, this kind of behavior just serves to create further barriers to the possibility of cooperative interaction. What is needed is to move toward the other 
person rather than away, and not only in an obvious physical sense. A good way to accomplish this symbolically is to let down one's defenses and open up psychologically, by trying to share thoughts, feelings, attitudes, and beliefs as much as possible. This does not, of course, mean that one immediately admit to one's partner that one thinks she is acting obnoxiously and selfishly. It does mean sharing experiences that seem to match those of one's partner, talking about transactions on the desk, patron behavior, "shop talk," or simply what kind of weekend one had. One recent study has shown that selfdisclosure is inversely related to competitiveness and that the more self-disclosure in a relationship, the closer its members feel to one another (Busse, 1993).

\section{PARADOXICAL RECIPROCITY}

Perhaps the most invidious aspect of competitive behavior is that it has a tendency to spiral, to feed on itself. This is because many people will behave competitively when confronted with competitive behavior on the part of their partner. In order to break the spiral, it may be necessary to behave in a paradoxical manner. Every time one's partner acts in a competitive way, instead of retaliating with similar behavior, reciprocate in as cooperative a way as possible (Riordan, 1986). By avoiding negative reciprocity, not only is escalation averted, but the way for new possibilities opens up. Acting in an accommodating and helpful manner makes it easier for one's partner to reciprocate that kind of behavior and has a tendency to create a positive interdependence. One's partner comes to depend on one for one's prosocial behavior which ironically gives one greater control over the behavior of one's partner. Simply acting in a negative way only results in greater conflict or a stalemate. Even the most competitive partners will likely respond 
to cooperative behavior in order to increase their chances of realizing some degree of civility and decency and avoid the situation deteriorating into open confrontation or a chilly standoff.

\section{POSITIVE REINFORCEMENT}

In addition to behaving in as positive and cooperative a manner as possible, it also helps to encourage one's partner to behave cooperatively. An effective way to accomplish this is through positive reinforcement. Every time one's partner acts in a cooperative manner or behaves in any way that approximates cooperation, one should immediately encourage the behavior in whatever way seems most appropriate (Heitler, 1990). Reinforcement can be verbal, such as an enthusiastic "thanks" or "much appreciated," or tactile, as in the case of an affectionate touch, pat, or smile (though one should be cautious about initiating any gesture that could be misinterpreted as a form of sexual harassment) or edible, such as gum, mints, etc. Psychologists recommend that whatever reinforcement one uses should include a description of the behavior one is trying to encourage, for example "I really appreciate you covering the phone while I was trying to help that patron."

\section{METACOMMUNICATION}

If all the preceding interventions fail, one can try metacommunication. This simply means communicating about communication, about the relationship itself (Fogel, 1997). This is an intervention of last resort because if not used properly, it may elicit a strong negative response. If deemed inappropriate or offensive, it may result in denial, 
aggression, or withdrawal on the part of one's partner. The timing of the intervention can be critical, as well as the tone and manner that one uses. It helps to prepare mentally by using self-talk to rehearse how one will verbalize one's feelings about the relationship and about one's discomfort with rivalry. One needs to be assertive, without being aggressive. Psychologically, there is a natural fear of making one's partner feel uncomfortable, and of creating a scene. Above all, there is the fear of making matters worse if the partner does not agree with one's assessment of the situation. One has to wait for the optimal time as well. Confronting a partner when there are patrons waiting for help, the phone is ringing, and there are five minutes left to the desk shift is probably not an ideal time. One needs to wait patiently for the right opportunity, though it should be as soon after the offending behavior as possible, while it is still fresh in both partners' minds. It also helps to be able to clearly articulate what the offending behavior is and how one would like it to change.

\section{BEYOND COOPERATION AND COMPETITION: CULTIVATING SYNERGY AND FLOW}

In some instances when working at the reference desk two librarians will develop a certain rapport or chemistry with one another. Each librarian seems to possess an intuitive understanding of when and how much support to lend their partner. The suggestions of one partner will often spark ideas or solutions in the other partner that might not have been possible had the person been working alone. This result is synergy, a partnership in which the joint efforts of the two librarians is more effective than either would be by themselves (Covey, 1996). 
Is it possible to cultivate synergy at the reference desk? First, developing a synergistic relationship between desk partners begins with an awareness of synergy itself, that it does exist and is a worthwhile goal. Second, while working together, try to become aware of one's partner's strengths as well as his weaknesses. Third, evaluate what one's strongest areas of expertise are, and one's weakest. Fourth, compare one's and one's partner's abilities and look for ways they might complement, enhance, and reinforce each other.

Once one has completed one's analysis, one may then begin to develop a sense of those occasions when it is appropriate to give one's partner professional autonomy, and other instances when one's partner could be helped by one's own expertise. When in doubt, it may be better to give one's partner the benefit of the doubt and not intervene in a reference transaction. If the subsequent course of the transaction ends unsuccessfully, one can try to intervene tactfully in order to prevent a patron from going away dissatisfied. But some librarians who feel strongly about professional autonomy may prefer to wait until afterward to make suggestions.

It is possible for two partners who are in tune with each other to go beyond synergy and enter a state of flow if the conditions are right. Flow is a mental state that occurs when one is totally engaged in what one is doing, and loses self-consciousness and a sense of time (Lefevre, 1988). The flow state may be triggered by one or more complex questions at the desk. This creates a challenge that both partners naturally respond to. These environmental demands challenge the capacity of both partners simultaneously. In order to master the situation there may be a heightened need for interactivity and responsiveness between two partners. Faced with such a situation, cooperative partners 
will spontaneously snap into action and initiate an interactive mutual effort in which they become totally engaged and focused on answering the question or questions.

In this state they exchange information and skills, bouncing leads and sources off one another, and all the while exhibiting an almost uncanny ability to anticipate each other's needs. This jointly intense pursuit of common goals and activities is called "flow," a psychological state in which two partners become so completely absorbed in their work and so totally in tune with one another that there is an effortless, harmonious rhythm and clockwork to their interaction. It is almost as if there are two minds working as one, a state when challenges and skills are perfectly matched with demands at the desk. Admittedly, this is not something easily achieved, but it illustrates one highly positive outcome that can result when cooperation is taken to its extreme. Unlike cooperation, flow is not something that can be readily cultivated. It is in part a function of the degree of cooperation and rapport enjoyed by two partners as well as the demands of the situation.

\section{CONCLUSION}

Cooperation and competition at the reference desk is a topic that has received little attention in the library literature, and this paper represents an initial attempt to outline the nature of cooperation and competition among librarians. An effort has been made to explain the dynamics of cooperative and competitive processes among librarians. The factors that contribute to cooperative and competitive desk behavior were discussed. A series of cognitive and behavioral interventions aimed at reducing competitive behavior was offered as a practical strategy for helping to change a competitive desk 
situation to a more cooperative one. Two very desirable outcomes of high cooperation, synergy and flow, were also discussed.

These interventions have been presented in as logical a sequence as possible, so that a librarian may attempt to solve the problem in a relatively logical, methodical way. Many of these techniques have proved effective in treating conflict situations that couples experience, and thus may be generalizable to the reference desk environment. However, no one has tested their efficacy in a library setting, and further research is needed to determine how useful such interventions might be. Until then, this paper seeks to offer the reader an initial set of tools for working with a complex and difficult interpersonal situation that many reference librarians are likely to encounter at some point in their careers. 


\section{$\underline{\text { References }}$}

Argyle, Michael (1991), Cooperation: The Basis of Sociability .London: Routledge.

Bagwell-Reese, Mary Kate, and Brack Gregory (1997), “The Therapeutic Use of

Reframing and Worldview in Mental Health Counseling," Journal of Mental Health

Counseling 19 (January), 78-86.

Baucom, Donald H., and Lester, Gregory W. (1986), “The Usefulness of Cognitive

Restructuring as an Adjunct to Behavioral Marital Therapy,” Behavior Therapy 17

(September), 385-403.

Baucom, Donald H., Sayers, Steven L., and Duke, Autumn (1989), “Attributional Style and Attributional Patterns Among Couples," Journal of Personality and Social Psychology 56 (April), 596-607.

Braver, Sanford L., and Barnett, Bruce (1976), "Effects of Modeling on Cooperation in a Prisoner's Dilemma Game," Journal of Personality and Social Psychology 33 (February), 161-169.

Burk, Edward, Randolph, Daniel Lee, and Probst, Charles (1985), "Effects of Several Thought Stopping Treatments on Worry Cognitions," Psychology, A Quarterly Journal of Human Behavior 22, 31-38.

Busse, Wilfried M. and Birk, Janice M. (1993), “The Effects of Self-Disclosure and Competitiveness on Friendship for Male Graduate Students Over 35," Journal of College Student Development 34 (May), 169-174. 
Carlson-Sabelli, Linnea (1989), "Role Reversal: A Concept Analysis and

Reinterpretation of the Research Literature," Journal of Group Psychotherapy, Psycodrama and Sociometry 41 (Winter), 139-152.

Cialdini, R.B., Schaller, M., Houlihan, D., Arps, K., Fultz, J., and Beoman, A.J. (1987), “Empathy Based Helping: Is It Selflessly or Selfishly Motivated?" Journal of Personality and Social Psychology 52 (April), 749-58.

Covey, Stephen (1996), "The Spirit of Synergy," Incentive 170 (September), 25. Csikzentmihalyi, Mihaly (1997), Finding Flow: The Psychology of Engagement with Everyday Life. New York: Basic Books.

Fogel, Alan, and Branco, Angela Uchoa (1997), "Metacommunication as a Source of Indeterminism in Relationship," in Dynamics and Indeterminism in Developmental Social Processes, edited by Alan Fogel, Maria C.D.P. Lyra, and Jaan Valsiner. Mahwah, New Jersey: Lawrence Erlbaum Associates Publishers, 65-92. Goffman, Erving (1959), The Presentation of Self in Everyday Life. Garden City, N.Y.: Doubleday.

Good, D.A. (1991), "Cooperation in a Microcosm: Lessons from Laboratory Games," in Cooperation and Prosocial Behavior, edited by Robert A. Hinde and Jo Groebel. Cambridge: Cambridge University Press, 224-237.

Guidano, Vittorio, F. (1995), "Self-Observation in Constructionist Psychotherapy," in Constructivism in Psychotherapy, edited by Robert A. Neimeyer and Michael J. Mahoney. Washington, D.C.: American Psychological Association, 155-168. 
Heitler, Susan (1990), From Conflict to Resolution: Strategies for Diagnosis and Treatment of Distressed Individuals, Couples, and Families. New York: W.W. Norton.

Houston, John M., Farese, Danielle M., La Du, Terence J. (1992), “Assessing Competitiveness: A Validation Study of the Competitiveness Index," Personality and Individual Differences 13 (October), 1153-1156.

Kelley, H.H. and Stahelski. A.J. (1970), “Social Interaction Basis of Cooperators' and Competitors' Beliefs About Others," Journal of Personality and Social Psychology 16 (September), 66-91.

Knight, George P. and Chao, Chia-Chen (1989), "Gender Differences in the Cooperative, Competitive, and Individualistic Social Values of Children," Motivation and Emotion 13 (June), 125-141.

Le Fevre, Judith (1988), "Flow and the Quality of Experience During Work and Leisure," in Optimal Experience: Psychological Studies of Flow in Consciousness, edited by Mihaly Csikszentmihalyi and Selega Isabella Csikszentmihalyi. New York, N.Y.: Cambridge University Press, 307-318.

Lester, David (1992), "Cooperative/Competitive Strategies and Locus of Control," Psychological Reports 71 (October), 594.

Magaletta, Philip R. and Oliver, J.M. (1999), “The Hope Construct, Will, and Ways: Their Relations with Self-Efficacy, Optimism, and General Well Being," Journal of Clinical Psychology 55 (May), 539-551.

Mander, Gertrud (1991), "Some Thoughts on Sibling Rivalry and Competitiveness," British Journal of Psychotherapy 7 (Summer), 368-379. 
Newton, Deborah A. and Burgoon, Judee (1990), "Nonverbal Conflict Behaviors:

Functions, Strategies and Tactics," in Intimates in Conflict: A Communication Perspective, edited by Dudley D. Cahn. Hillside, New Jersey: Lawrence Erlbaum Associates, 77-104.

Riordan, Anthony, Severinsen, Norman, Martin, Don, and Martin, Maggie (1986), "Understanding the Use of Paradox in Counseling," Family Therapy 13, 239-248. Ward, Edward A. (1995), "Correlates of Motivation for Competitive or Cooperative Strategy Among Employed Adults," Journal of Organizational Behavior 16 (January), 93-100.

Wollman, Neil, Kelly, Benita M., and Borders, Kenneth S. (1994), "Environmental and Interpersonal Predictors of Reactions to Potential Territorial Intrusions in the Workplace, Environment and Behavior 26 (March), 179-194. 